\title{
Exploring the Training Mode of Applied Innovative Talents Facing the Construction of Innovative Country
}

\author{
Jun Chen", Xiangxia Cui \\ College of Physics and Electronic Engineering, Taishan University, 271021, China. \\ E-mail: nankaichen@163.com
}

\begin{abstract}
With the continuous development of the Chinese economy, the continuous improvement of the education model, and the increasing demand for innovative talents in the society, the cultivation of applied innovative talents in China is gradually increasing, and the management model is gradually improving. As the main base for cultivating innovative talents, colleges and universities have placed new demands on teachers' education methods while focusing on the cultivation of students' innovative ability. This article takes colleges and universities as an example, analyzes the current cultivation model of innovative talents, and puts forward reform suggestions on the problems faced by the management model.
\end{abstract}

Keywords: Applied Innovative Talents, Training Mode

\section{Introduction}

Under the background of the country's reform of the education model, colleges and universities, as the main incubator for the cultivation of applied innovative talents, are constantly exploring new ways of reforming education. Based on the understanding of the concept and characteristics of national application-oriented innovative talents, and the recognition that application-oriented innovative talents play an important role in China's socialist construction, We can understand that the educational reform carried out by colleges and universities must always aim at students, cultivate their ability to build a plastic knowledge framework, enhance their sense of responsibility to create innovative countries, provide them with guidance for innovative development, and enable them to have innovative thinking and innovation ability. At the same time, we should also pay attention to the improvement of the quality of college teachers and build a high-quality service team for the cultivation of innovative talents. From a national perspective, in view of the current status of college students at this stage, the country should increase its investment in colleges and universities, use the most innovative education methods to guide students, and help them become innovative talents needed by the country ${ }^{[1]}$.

\section{The limitations and challenges faced by colleges and universities in cultivating application-oriented innovative talents}

\subsection{Unsuitable college management plan for students}

In recent years, colleges and universities have continued to expand enrollment, and the number of college students has continued to increase. However, due to the lack of students' knowledge literacy, their innovative quality has not increased with the expansion of colleges and universities. Therefore, in the process of college management of students, how to cultivate students' innovative ability has become a problem. In practice, some colleges and universities adopt stocking management and cannot meet strict requirements for students. This stocking management model leads to the loose character of students, which cannot make them form good self-learning ability and innovation ability. Especially

Copyright (C) 2020 Jun Chen et al.

doi: 10.18282/le.v9i5.1256

This is an open-access article distributed under the terms of the Creative Commons Attribution Non-Commercial License

(http://creativecommons.org/licenses/by-nc/4.0/), which permits unrestricted non-commercial use, distribution, and reproduction in any medium, provided the original work is properly cited. 
for some students with low self-control ability, it is even more unable to improve their sense of social responsibility to become innovative talents. And some colleges and universities adopt too strict methods in the management mode, which will hinder the personal development of students and suppress their enthusiasm.

\subsection{Unprofessional teaching staff}

Because of the lack of the quality of students in the overall colleges and universities, each college also has certain difficulties in the management process. At the same time, because the school's salary for college teachers is not high, and the teachers are not regulated, the entire education team is not aggressive, resulting in a low collective motivation of teachers and students.

\section{The exploration of application-oriented innovative talent training model for the construction of innovative country}

\subsection{Improving the management capabilities of colleges}

\subsubsection{Formulating corresponding rules and regulations}

Only by formulating rules and regulations that meet the requirements for the cultivation of application-oriented innovative talents can colleges and universities receive standardized and innovative management of the education received by their students. Schools should always take the interests of students as the starting point, not just their own interests. In recent years, after continuous practice, various colleges and universities have formulated a lot of rules and regulations according to their own conditions to regulate the behavior of students and change their bad behavior habits in the past, so that the national legal system can be displayed in colleges and universities ${ }^{[2]}$.

\subsubsection{Improving students' own literacy and cultivate innovative ability}

Colleges and universities should base on the different characteristics among students, and combine the characteristics of the country's requirements for application-oriented innovative talents, from the aspects of knowledge reserve, innovative thinking, ability structure, etc., to enhance students' innovative thinking and the social responsibility of building an innovative country . Only in this way can students' creativity be effectively improved.

\subsubsection{Establishment of new management and teaching concepts}

Colleges and universities should establish a new teaching concept, change the original management system, and adhere to the scientific management concept in the process of giving students innovative guidance. In the development process of each school, we must take students as the foundation, ensure students' dominant position in the school, and truly understand the needs of students in practice and innovation.

At the same time, colleges and universities should be guided by the cultivation of students' innovative ability, and teachers should achieve the goal of student self-management in a variety of teaching methods, so as to improve students' initiative and enthusiasm. In the process of group management, the thematic activities on how to improve innovation literacy can be discussed in groups to cultivate students' subjective awareness and innovation ability ${ }^{[3]}$, and at the same time enable them to get a sense of participation and achievement. In addition, by organizing more competitions on cultivating students' innovative applications, students' awareness of innovation can also be improved.

\subsubsection{Implementation of professional innovation guidance in practice}

In the process of cultivating students' innovative quality, colleges and universities should carry out targeted training, not just to talk about innovative education, but to implement it in practice ${ }^{[4]}$. First, colleges and universities should actively build practical teaching platforms and open laboratories reasonably to provide opportunities for students to practice; secondly, colleges and universities should actively formulate and implement college students' extracurricular scientific and technological innovation and social practice training plans to enable students to gain more practical experience. Finally, colleges and universities should actively cooperate with enterprises to build engineering training centers, so that the students' engineering quality, professional and technical application ability, and the ability to analyze and solve practical engineering problems can be improved during the production internship process.

\subsection{Improving teachers' professional qualities}


As a person who teaches knowledge to students, if the teacher's innovation ability fails to meet the requirements, it will not only affect the teaching effect, but also the students' innovation ability. Therefore, colleges and universities should actively enhance the innovation ability of the teaching team and strengthen the training of teachers' innovative qualities, such as hiring some professional and innovative teachers, training the school's teacher team, establishing a comprehensive examination system for improving teachers' innovation ability, and formulating Special assessment system. Through these measures, the innovation literacy of college teachers will be further improved, and they will be able to better guide students in innovative practice.

In the teaching process, teachers need to establish correct values for students, develop students' innovative potential, and guide students to engage in innovative exchanges by cultivating students' own interests and other positive methods, so that students' exploration of innovative applications becomes normal. In daily life, teachers should also actively understand students' ideas about innovation and provide targeted guidance, which will not only enhance students' sense of innovation, but also deepen the emotions between teachers and students.

\subsection{Focusing on students' innovative practice}

As major bases for cultivating innovative talents, universities should actively promote the development of innovative practices, integrate practical resources, provide students with more opportunities for innovative practices, provide them with more detailed technical and innovative guidance, and help students expand contact with society ${ }^{[5]}$. As a teacher, you should actively guide students to explore innovative practice, so as to arouse students' enthusiasm in the process of innovative practice and improve their overall innovation quality. As a student, you should strive to solidify your basic knowledge of innovation and improve your ability in innovation through continuous learning. At the same time, in the process of learning, students must not only earnestly study the innovative theoretical knowledge in the textbooks, but also actively participate in innovative practice and strive to become an application-oriented innovative talent.

\subsection{The construction of informatization training platform-Internet-based campus learning platform}

With the rapid development of my country's Internet technology, the implementation of Internet-style education and learning management in colleges and universities has gradually become the mainstream. Many schools and enterprises use the Internet to conduct academic and work exchanges, which not only makes the process of instructing students innovatively more convenient, but also more efficient. In terms of education and teaching, if students have any questions they don't understand during the course, they can promptly ask the teacher on the platform, and teachers will answer in time when they see it, which will save a lot of time. In addition, students can learn innovative theories and exchange their learning experience through the platform in the classroom, and teachers can publish original innovative ability courses on the platform. Students can adjust the speed of the rhythm of listening to lessons according to their learning habits, so as to lay a solid theoretical support in the process of innovative practice ${ }^{[6]}$.

Finally, the Internet-based teaching platform can integrate students' demand for innovative knowledge, which not only makes it easier for teachers to understand the needs of students, but also enables students to learn more diverse and comprehensive innovative knowledge. All in all, the emergence and popularization of the Internet-based campus learning platform will be more conducive to the cultivation of applied innovative talents in colleges and universities.

\section{Conclusion}

The cultivation of application-oriented innovative talents is the focus of the work of universities in the country. The country's demand for application-oriented innovative talents is constantly increasing with the development of the economy. The country should not only improve the innovation ability of college students, but also improve the school's own teaching management model, strengthen the construction of innovation education management in colleges and universities, implement the educational concept guided by innovation education, and pursue innovative development. The education management and personnel training of colleges and universities must always be guided by the requirements of the country for innovative technical talents, so as to cultivate a batch of excellent applied innovative talents for the country. 


\section{Acknowledgments}

School Reform Project:The Construction and Empirical Research of College Students' Innovative Ability Training System under the Background of New and Old Kinetic Energy Conversion - Take Taishan University as an example (201818); Shandong Soft Science Project: Research on the Cooperation Mechanism and Countermeasures of Shandong Local Colleges and Universities under the Background of New and Old Kinetic Energy Conversion (2018RKB01448).

\section{References}

1. Xiong Shan. Exploration of practical teaching reform of marketing majors in colleges and universities from the perspective of applied innovative talent cultivation[J]. Industry and Technology Forum, 2018(4): 7.

2. Zhang Huixin. A review of research on practical teaching models for the cultivation of innovative applied talents[J]. "Education and Teaching Forum", 2017(39): 6.

3. Guan Fang, Hu Hongzhi, Guo Qing. A review of the research on the practical teaching model for the cultivation of innovative applied talents [J]. Periodical thesis "Experimental Technology and Management", 2016(17): 3.

4. Liu Jin. Research on the practical teaching model for the cultivation of applied innovative talents [J]. "Science Outlook", 2018(4): 7.

5. Zhang Ping. Research on the teaching model of the cultivation of applied innovative talents [J]. "Liaoning Silk", 2016(2): 54.

6. Yan Xinping, Xie Junlin, Li Zhifeng. Research on practical teaching reform of the cultivation of applied innovative talents [J]. "The Road to Success", 2016(4): 67. 